\title{
The effects of empathy techniques education for nurses on resilience and spiritual well-being among mothers with preterm neonates in neonatal intensive care unit
}

\author{
Mitra Mahdian $^{\left.1^{(}\right)}$, Narges Sadeghi $^{2^{*}}{ }^{(\mathbb{D}}$, Mina Mohammady $^{(\mathbb{D}}$ \\ ${ }^{1}$ MSc student of pediatric nursing, Isfahan (khorasgan) Branch, Islamic Azad University, Isfahan, Iran \\ ${ }^{2}$ Community Health Research Center, Isfahan (Khorasgan) Branch, Islamic Azad University, Isfahan, Iran
}

\begin{abstract}
Background and aims: Communication is a key component of professional nursing care. This study aimed at evaluating the effects of empathetic techniques education for nurses on resilience and spiritual well-being (SWB) among mothers with preterm neonates in neonatal intensive care unit (NICU).

Methods: This cluster randomized controlled trial was conducted in 2018 using a two-group pretest-posttest design. Main participants were 68 mothers of preterm neonates in the NICUs of Montazeri and Amin hospitals in Isfahan, Iran. Nurses in the intervention hospital (i.e. Montazeri hospital) were provided with empathy techniques education in five weekly sessions in one month. After that, mothers in both groups completed the Connor-Davidson Resilience Scale and the SWB Scale both at the time of their neonates' NICU admission and at the time of their neonates' NICU discharge. Data were analyzed using the SPSS software (v. 22.0).

Results: The pretest mean scores of resilience and SWB were respectively $79.74 \pm 12.78$ and $175.6 \pm 11.95$ in the control group and $78.0 \pm 16.9$ and $176.67 \pm 16.0$ in the intervention group. At posttest, these values were $78.32 \pm 12.12,176.53 \pm 11.40,92.0 \pm 13.77$, and $186.0 \pm 12.5$, respectively. Although the betweengroup differences respecting the pretest mean scores of resilience and SWB were not statistically significant $(P>0.05)$, the posttest mean scores of resilience and SWB in the intervention group were significantly greater than the control group $(P<0.05)$.

Conclusion: Empathy techniques education is effective in significantly improving resilience and SWB among the mothers of preterm neonates in NICU. Therefore, this intervention is recommended for nurses in NICU. Keywords: Empathy education, Resilience, Spiritual well-being, Mothers with preterm neonates
\end{abstract}

*Corresponding Author: Narges Sadeghi, Community Health Research Center, Isfahan (Khorasgan) Branch, Islamic Azad University, Isfahan, Iran

Email: n45sadeghi@yahoo. com

Received: 18 August 2020 Accepted: 20 October 2020 ePublished: 30 March 2021

\section{Introduction}

The use of communication skills is an essential and integral part of the nursing profession and is one of the important tools for nurses to support patients and their families (1). Communication skills are an important element in nursing care and nursing education. In this regard, effective communication is the most important factor in maintaining quality nursing care (2). However, nurses in many cases have not received special training in communication skills (3).

Communication skills are very important in some areas. One of these departments is the neonatal intensive care unit (NICU) (4). Preterm birth is a stressful condition for parents, particularly mothers. It is usually associated with senses of tension, depression, despair, failure, and unsuccessfulness (5). Preterm birth may necessitate hospitalization in NICU which is in turn associated with concerns over neonatal health, neonate-mother separation, and psychoemotional problems such as stress for mothers (6). Acute physical and mental tension induced by a preterm birth and hospitalization in NICU can affect mothers for a long time, alter their relationship with their neonates, and impair their physical and mental functions (7). The World Health Organization reported that $10 \%$ of pregnant women and $13 \%$ of postpartum women throughout the world experience mental disorders, particularly depression (8).

The attempt to reduce the effects of tensions is called coping. A study showed religious coping as the most important emotion-focused coping strategy among mothers with preterm neonates and reported that religious beliefs help fulfill most emotional, moral, and spiritual needs (9). Spiritual well-being (SWB) is a concept with close relationships with religiosity and religious beliefs (10). It consists of a religious component and a psychosocial component (11). A study found that SWB had significant positive relationship with life satisfaction among the mothers of children with mental retardation. That study also reported that religiosity enables individuals to control their stress- and disabilityrelated physiological, cognitive, and emotional problems, improves their self-confidence, hope, and power, and acts as an important source of coping and support (12).

Resilience is another factor with significant relationships with coping, PSW, and religious beliefs (13). In adverse conditions, resilient individuals are more likely to explore 
meaning. Their faith improves their tolerance towards problems and helps them overcome their challenges. Moreover, their spiritual beliefs and their relationship with a Supreme Being promote their resilience (14). By definition, resilience is the ability to cope with the consequences of adverse events such as stress and changes (15). It is also defined as the ability to regain normal functioning after adverse events and as the use of strategies to produce positive outcomes and improve quality of life (16).

A study reported a significant inverse relationship between resilience and psychological problems and noted that resilience promotion would be associated with greater resistance to psychological problems (17).

Strong professional support by healthcare providers is essential to promote resilience, SWB, and coping among the parents of children with serious health problems (18), such as the mothers of neonates in NICU. Nurses are in a good position for supporting these mothers (19). Effective interpersonal communication is a prerequisite for providing strong support to nursing clients (4). Studies showed that patient-centered communication can improve the quality of information transfer to patients and facilitate positive and supportive relationships with them (20). Effective communication also improves the quality of nursing care (2) and is considered as an inseparable part of quality nursing care delivery (1).

Empathy is a key component of nurses' effective communication with patients (21). However, nurses usually do not receive quality and systematic education about communications skills (3). A study reported that without quality education, healthcare providers may be unable to identify the symptoms of emotional problems among their clients and provide them with appropriate empathetic responses (22). Another study in China also reported that nurses had limited abilities for evaluating the emotional status of patients and their family members (23). Meanwhile, clients who are under stress may not completely communicate their feelings with nurses (24). Therefore, nurses need to receive quality education to develop their professional skills for establishing effective empathetic communication with their clients and accurately identifying and managing their emotional problems (4). This study aimed to evaluate the effects of empathetic techniques education for NICU nurses on resilience and SWB among mothers with preterm neonates in NICU.

\section{Materials and Methods}

This cluster randomized controlled trial was conducted in 2018 using a two-group pretest-posttest design. Participants were NICU nurses and the mothers of preterm neonates in NICU selected from Montazeri and Amin hospitals, Isfahan, Iran. These two hospitals were conveniently selected and then, the coin tossing method was used to randomly allocate one hospital to a control and the other to an intervention group. This type of allocation was used to prevent between-group information leakage (25). After the study intervention, the mothers of preterm neonates were selected for data collection.

Eligibility criteria for nurses were bachelor's degree or higher in nursing, employment in NICU with a NICU work experience of at least one year, and no history of participation in empathy-related educational courses. Inclusion criterion for mothers was having a preterm neonate in NICU with a predicted NICU stay of at least seven days.

Using the following formula and with a confidence level of 0.95 , a power of 0.80 , a $d$ value of $70 \%$ of standard deviation, and an attrition rate of $10 \%$, sample size was determined to be 36 per groups.

$$
n=\frac{2 \sigma^{2}\left(z_{1-\alpha / 2}+z_{1-\beta}\right)^{2}}{\delta^{2}}
$$

\section{Intervention}

All eligible NICU nurses of Montazeri hospital were selected and provided with education about empathy techniques in five weekly sessions held in one month (4). Meanwhile, nurses exercised the techniques under the guidance and the supervision of the researcher in order to get ready for independent use of the techniques. The empathy techniques education intervention was developed based on two previous studies $(26,27)$ and is shown in Table 1. Immediately after the one-month period of the nurses' education, they were asked to use the learned empathy techniques in their daily practice under the supervision of the researcher. After nurses' education, mothers who had preterm neonates in NICU were selected to complete the study instruments both at the time of their neonates' NICU admission and at the time of their neonates' NICU discharge. No empathybased intervention was provided to nurses in the control hospital. The mothers of the neonates in the NICU of the control hospital received routine care services and completed the study instruments at the time of their neonates' NICU admission and NICU discharge.

\section{Data collection}

Study instruments were a demographic questionnaire for nurses, a demographic questionnaire for mothers, the Connor-Davidson Resilience Scale, and the SWB scale. The demographic questionnaires included items on age, educational level, family income, employment status, and neonate's birth rank.

The Connor-Davidson Resilience Scale was developed in 2003 through reviewing resilience-related literature published in 1979-1991 (28). We used the 25-item version of this scale. Its items were scored on a five-point scale from 1 ("Completely wrong") to 5 ("Always right"), resulting in a possible total score of 25-125 with higher scores showing greater resilience. The psychometric properties of the Persian version of this scale were confirmed in a former study with a Cronbach's alpha of 0.942 (29).

The SWB Scale was developed based on the 
Table 1. The content of the empathy education sessions

\begin{tabular}{lll}
\hline Session & Objectives & Assignments \\
\hline 1 & $\begin{array}{l}\text { Presentation of the goals of the sessions } \\
\text { Defining the concept of empathy and explaining its effects on patients }\end{array}$ & $\begin{array}{l}\text { Defining the concept of empathy and the effects that nurses } \\
\text { 'empathy has on patients' recovery. Talk about nurses' } \\
\text { experience of empathizing with patients }\end{array}$ \\
\hline 2 & $\begin{array}{l}\text { Explaining empathy techniques and their categorization } \\
\text { explaining non-verbal empathy techniques such as appropriate body orientation, }\end{array}$ & Self-study about empathy techniques \\
\hline 4 & $\begin{array}{l}\text { Explaining verbal empathy (or active listening) techniques including transitional } \\
\text { phrases, parroting response, paraphrasing, and reflection of feelings }\end{array}$ & Exercising verbal empathy techniques \\
\hline 5 & Practical exercise of the techniques & Practical use of the techniques in the next work shift
\end{tabular}

recommended model of the National Interfaith Coalition on Aging and contains forty items scored on a five-point scale from 1 ("Completely disagree") to 5 ("Completely agree"). Therefore, the total score of the scale is $40-200$ with higher scores showing better SWB. The Cronbach's alpha and the test-retest correlation coefficient of the scale were 0.94 and 0.86 , respectively. Moreover, the score of the scale had significant positive correlation with the scores of the SWB Scale, the Satisfaction with Life Scale, and the Adherence to Religious Beliefs, and significant negative correlation with the score of mental disorders, confirming its acceptable convergent and discriminant validity. Exploratory and confirmatory factor analyses also confirmed its acceptable construct validity (10).

\section{Data analysis}

The SPSS software (v. 22.0) was used for data analysis. Data description was done using the measures of descriptive statistics, namely absolute frequency, relative frequency, mean, and standard deviation. Data normality was tested through the Kolmogorov-Smirnov test which showed that all study variables had normal distribution. Therefore, between-group comparisons were made using the Chi-square and the independent-sample $t$ tests as well as the analysis of covariance and Mann-Whitney U test. Within-group comparisons were also made using the paired-sample $t$ test.

\section{Results}

Sixty-eight mother-infant were included in the trial (Figure 1). The mean of mothers' age was $29.14 \pm 6.53$ years in the control group and $27.97 \pm 6.01$ years in the intervention group and most mothers were young. Moreover, all nurses in both groups were female. The results of the chi-square and the independent-sample $t$ tests revealed no significant differences between the groups in terms of mothers' age ( $P=0.44)$, educational level $(P=0.49)$, and their neonates' birth rank $(P=0.42)$, as well as nurses' employment status

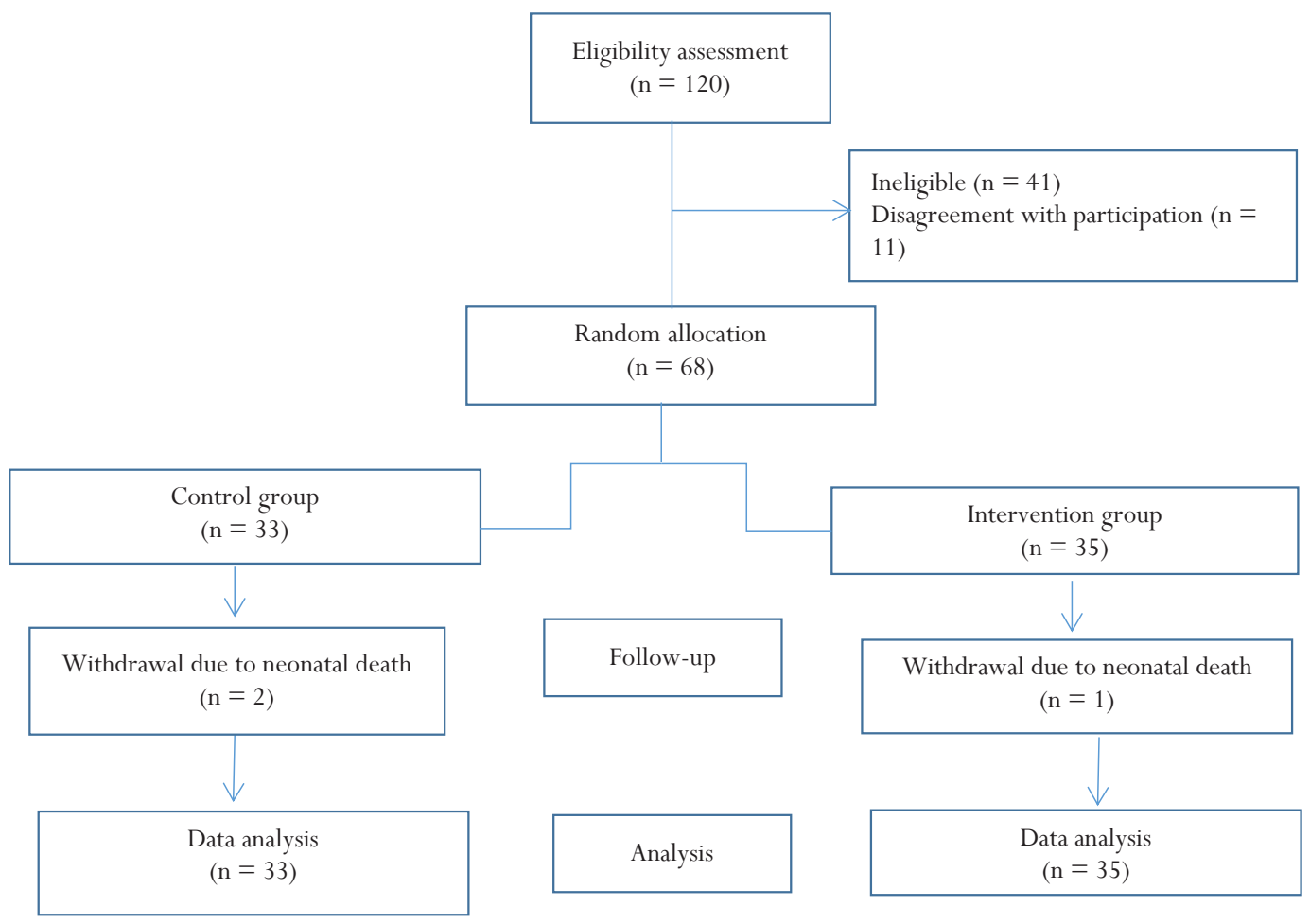

Figure 1. The flow diagram of the study. 
$(P=0.38)$ and educational level $(P=0.95$; Table 2$)$.

The independent-sample $t$ test revealed that there were no significant between-group differences respecting the pretest mean scores of resilience and SWB $(P>0.05)$. However, the posttest mean scores of resilience and SWB in the intervention group were significantly higher than the control group $(P<0.05$; Tables 3 and 4$)$.

\section{Discussion}

This study evaluated the effects of empathetic techniques education for NICU nurses on resilience and SWB among mothers with preterm neonates in NICU. Findings showed that empathy techniques education for NICU nurses significantly improved resilience and SWB among the mothers of preterm neonates in NICU. In line with our findings, a previous study indicated that communication skills education significantly improved nurses' ability to respond with empathy to parents' emotions in NICU from $20 \%$ to $54 \%$ and significantly reduced their negligence towards parents' emotions from $63 \%$ to $27.5 \%(P=0.43)$. That study also reported that as parents have close relationships with nurses during their neonates' NICU

Table 2. The demographic characteristics of participating nurses and mothers

\begin{tabular}{|c|c|c|c|c|c|c|c|c|}
\hline \multirow{3}{*}{ Characteristics } & & \multicolumn{6}{|c|}{ Groups } & \multirow{3}{*}{$P$ value } \\
\hline & & \multicolumn{2}{|c|}{ Intervention } & \multicolumn{2}{|c|}{ Control } & \multicolumn{2}{|c|}{ Total } & \\
\hline & & No. & $\%$ & No. & $\%$ & No. & $\%$ & \\
\hline \multirow{4}{*}{ Mother's educational level } & Primary & 3 & 8.6 & 4 & 12.2 & 7 & 10.3 & \multirow{4}{*}{$0.49^{*}$} \\
\hline & Guidance school & 5 & 14.3 & 6 & 18.1 & 11 & 16.2 & \\
\hline & Diploma & 18 & 51.4 & 16 & 48.5 & 34 & 50 & \\
\hline & University & 9 & 25.7 & 7 & 21.2 & 16 & 23.5 & \\
\hline \multirow{4}{*}{ Neonate's birth rank } & First & 14 & 40 & 18 & 54.6 & 32 & 47.1 & \multirow{4}{*}{$0.42^{*}$} \\
\hline & Second & 12 & 34.3 & 6 & 18.2 & 18 & 16.4 & \\
\hline & Third & 7 & 20 & 8 & 24.2 & 15 & 22.1 & \\
\hline & Fourth and higher & 2 & 5.7 & 1 & 3 & 3 & 4.4 & \\
\hline \multirow{3}{*}{ Family income } & Sufficient & 6 & 17.1 & 6 & 18.2 & 12 & 17.6 & \multirow{3}{*}{$0.54^{*}$} \\
\hline & Relatively sufficient & 24 & 68.6 & 19 & 57.6 & 43 & 63.6 & \\
\hline & Insufficient & 5 & 14.3 & 8 & 24.2 & 13 & 19.2 & \\
\hline \multirow{2}{*}{ Nurse's educational level } & Bachelor's & 18 & 81.8 & 15 & 83.3 & 33 & 82.5 & \multirow{2}{*}{$0.95^{*}$} \\
\hline & Master's & 4 & 18.2 & 3 & 16.7 & 7 & 17.5 & \\
\hline \multirow{2}{*}{ Nurse's employment status } & Permanent & 8 & 36.4 & 9 & 50 & 17 & 42.5 & \multirow{2}{*}{$0.38^{* *}$} \\
\hline & Contractual & 14 & 63.6 & 9 & 50 & 13 & 57.5 & \\
\hline
\end{tabular}

* The results of the Mann-Whitney $U$ test; ${ }^{* *}$ The results of the chi-square test.

Table 3. Between- and within-group comparisons respecting mothers' mean scores of resilience and its dimensions

\begin{tabular}{|c|c|c|c|c|c|c|}
\hline \multirow{3}{*}{ Time } & \multirow{3}{*}{ Resilience dimensions } & \multicolumn{4}{|c|}{ Groups } & \multirow{3}{*}{ Test results } \\
\hline & & \multicolumn{2}{|c|}{ Intervention $(n=35)$} & \multicolumn{2}{|c|}{ Control $(n=33)$} & \\
\hline & & Mean & SD & Mean & SD & \\
\hline \multirow{6}{*}{ Before } & Personal competence & 26.45 & 6.59 & 25.48 & 5.36 & \multirow{5}{*}{$t=0.07$} \\
\hline & Trust in one's instincts and tolerance of negative effect & 19.97 & 5.26 & 19.98 & 3.84 & \\
\hline & Positive acceptance of change and secure relationships & 15.69 & 3.6 & 16.18 & 3.65 & \\
\hline & Control & 9.46 & 2.67 & 9.58 & 3.72 & \\
\hline & Spiritual influences & 8.43 & 1.58 & 8.5 & 1.5 & \\
\hline & Total & 80.0 & 16.9 & 79.74 & 12.78 & $P=0.94^{*}$ \\
\hline \multirow{6}{*}{ After } & Personal competence & 29.81 & 5.42 & 25.03 & 5.38 & \multirow{5}{*}{$F=24.29$} \\
\hline & Trust in one's instincts and tolerance of negative effect & 23.26 & 4.77 & 19.63 & 3.18 & \\
\hline & Positive acceptance of change and secure relationships & 18.63 & 3.3 & 15.93 & 3.22 & \\
\hline & Control & 11.16 & 2.4 & 9.21 & 2.43 & \\
\hline & Spiritual influences & 9.17 & 1.07 & 8.52 & 1.52 & \\
\hline & Total & 92.02 & 13.77 & 78.32 & 12.12 & $P<0.001^{* *}$ \\
\hline
\end{tabular}

* The results of the independent-sample $t$ test; ${ }^{* *}$ The results of the analysis of covariance.

${ }^{a}$ The results of the paired-sample $t$ test 
Table 4. Between- and within-group comparisons respecting mothers' mean scores of SWB and its dimensions

\begin{tabular}{|c|c|c|c|c|c|c|}
\hline \multirow{2}{*}{ Time } & \multirow{2}{*}{ SWB dimensions } & \multicolumn{2}{|c|}{ Intervention $(n=35)$} & \multicolumn{2}{|c|}{ Control $(n=33)$} & \multirow{2}{*}{ Test results } \\
\hline & & SD & Mean & SD & Mean & \\
\hline \multirow{5}{*}{ Before } & Relationship with God & 47.2 & 3.2 & 46.9 & 3.9 & \multirow{4}{*}{$t=0.32$} \\
\hline & Relationship with self & 42.6 & 5.7 & 42.6 & 4.3 & \\
\hline & Relationship with others & 44.5 & 3.7 & 44.5 & 3.5 & \\
\hline & Relationship with nature & 42.2 & 5.5 & 41.5 & 4.06 & \\
\hline & Total & 176 & 16 & 175 & 12 & $P=0.75$ \\
\hline \multirow{5}{*}{ After } & Relationship with God & 48.7 & 2.4 & 46.7 & 3.5 & \multirow{4}{*}{$F=52.3$} \\
\hline & Relationship with self & 46.4 & 4.8 & 42.7 & 3.7 & \\
\hline & Relationship with others & 47.4 & 2.5 & 45 & 3.3 & \\
\hline & Relationship with nature & 44 & 4.8 & 42.18 & 3.8 & \\
\hline & Total & 186 & 12.5 & 176.5 & 11.4 & $P<0.001^{* *}$ \\
\hline Test results & & \multicolumn{2}{|c|}{$P<0.001^{\text {a }}$} & \multicolumn{2}{|c|}{$P=0.41$} & \\
\hline
\end{tabular}

* The results of the independent-sample $t$ test; ${ }^{* *}$ The results of the analysis of covariance.

a The results of the paired-sample $t$ test

stay, communication skills education for NICU nurses can improve their understating of parents' conditions, enhance parents' satisfaction, and encourage parents to engage in care delivery to their neonates (3). The most important causes of stress among the mothers of neonates in NICU are separation from their neonates, changes in their roles, despair over supporting their neonates against pain and painful procedures, and witnessing their neonates in painful conditions (30). Therefore, providing support to mothers can increase their self-efficacy, parental skills, and mental health, particularly during the first year after birth (31). Healthcare providers' support for mothers' engagement in neonatal care can also improve motherneonate attachment (32).

In a survey by Wigert et al through interviewing the parents of neonates in NICU about their experiences of nurses' communication with them also showed that providing parents with opportunities to communicate with nurses and express their emotions helped them feel empathized with. Moreover, that study showed that nurses' lack of hurry and prejudice in communication with parents created confident relationships and their empathetic relationships with parents reduced parents' stress (24). Another study on the mothers of children with autism also revealed that self-compassion training significantly increased their resilience (33). Similarly, a study showed that a nurse-delivered auditory visit with active listening significantly improved mood among the mothers of neonates in NICU (34). Active listening is a main component of empathetic communication.

In critical situations, families need effective interpersonal communication in order to restore their healthy conditions. Communication with others is a key factor in improving resilience in critical conditions and helps individuals gain others' support (35). National Prenatal Association in 2105 announced NICU nurses' communication with the mothers of neonates in NICU stabilizes mothers' mental and psychological conditions, reduces their stress, and improves their resilience and SWB (36). Nonetheless, nurses cannot independently obtain essential communication skills through daily practice and need quality education in this area (37). A study showed that communication skills education for nurses in NICU was effective in significantly improving their relationships with their colleagues and also with the mothers of neonates in NICU (4).

One of the strengths of this study was the use of random allocation. Of course, given the likelihood of betweengroup information leakage, randomization of individual participants to the study groups was not possible (25). Moreover, as the mothers of preterm neonates in the study setting attended NICU in all working shifts, they were very likely to receive care from nurses who had not received empathy techniques education.

\section{Conclusion}

This study suggests the effectiveness of empathy techniques education in significantly improving resilience and SWB among the mothers of preterm neonates in NICU.

\section{Conflict of Interests}

None.

Ethical Approval

This study has the approval of the Ethics Committee of Islamic

What does this paper contribute to the wider global clinical community?

- $\quad$ Strong professional support by healthcare providers is essential to promote resilience, spiritual wellbeing, and coping among the parents of children with serious health problems.

- Empathy techniques education is effective in significantlyimproving resilience and spiritual wellbeing among the mothers of preterm neonates in NICU. 
Azad University, Isfahan (Khorasgan) Branch, Isfahan, Iran (code: IR.IAU.KHUISF.1397.135). Informed consent was obtained from all participating nurses and mothers and they were ensured that participation in and withdrawal from the study would be voluntary and their data would be handled confidentially. Moreover, the participating mothers were ensured that their refusal of participation would have no negative effect on the course of treatments for their neonates. After the study intervention, empathy-related educational pamphlets were provided to participants in the control group.

\section{Acknowledgement}

This article sprang from a Master's thesis in Islamic Azad University, Isfahan (Khorasgan) Branch, Isfahan, Iran. The thesis was personally funded by the authors with no financial support from any organization. The authors would like to show their gratitude to all nurses and mothers who participated in the study as well as all individuals who helped them conduct the study.

\section{References}

1. Farmahini Farahani M, Kashaninia Z, Hosseini MA, Biglarian A. Impact of training communication skills to nurses on patients' satisfaction with nurse-patient relationship. Iranian Journal of Nursing Research. 2006;1(3):47-54. [Persian].

2. Mullan BA, Kothe EJ. Evaluating a nursing communication skills training course: the relationships between self-rated ability, satisfaction, and actual performance. Nurse Educ Pract. 2010;10(6):374-8. doi: 10.1016/j.nepr.2010.05.007.

3. Bry $K$, Bry $M$, Hentz $E$, Karlsson $H L$, Kyllönen $H$, Lundkvist $M$, et al. Communication skills training enhances nurses' ability to respond with empathy to parents' emotions in a neonatal intensive care unit. Acta Paediatr. 2016;105(4):397-406. doi: 10.1111/ apa.13295.

4. Shao YN, Sun HM, Huang JW, Li ML, Huang RR, Li $\mathrm{N}$. Simulation-based empathy training improves the communication skills of neonatal nurses. Clin Simul Nurs. 2018;22:32-42. doi: 10.1016/j. ecns.2018.07.003.†

5. Lindberg B, Ohrling K. Experiences of having a prematurely born infant from the perspective of mothers in northern Sweden. Int J Circumpolar Health. 2008;67(5):461-71. doi: 10.3402/ijch.v67i5.18353.

6. Parker L. Mothers' experience of receiving counselling/ psychotherapy on a neonatal intensive care unit (NICU). J Neonatal Nurs. 2011;17(5):182-9. doi: 10.1016/j. jnn.2010.12.001.

7. Tu MT, Grunau RE, Petrie-Thomas J, Haley DW, Weinberg J, Whitfield MF. Maternal stress and behavior modulate relationships between neonatal stress, attention, and basal cortisol at 8 months in preterm infants. Dev Psychobiol. 2007;49(2):150-64. doi: 10.1002/dev.20204.

8. World Health Organization. (2020). Maternal mental health. Access date:2020/05/12. Retriverd From: https://www.who.int/mental_health/maternal-child/ maternal_mental_health/en/.

9. Momenizadeh A, Zeraati H, Shahinfar J, Ghorbanzadeh M. Coping with stress in mothers of preterm infants hospitalized in the neonatal intensive care unit. Iranian Journal of Pediatric Nursing. 2017;4(1):23-8. doi: 10.21859/jpen-04014. [Persian].

10. Dehshiri GR, Najafi M, Sohrabi F, Taraghi Jah S. Construct and validate spiritual well-being scale among students. Psychol Stud. 2013;9(4):73-98. [Persian].

11. Ellison CG. Religious involvement and subjective wellbeing. J Health Soc Behav. 1991;32(1):80-99.

12. Narimani M, Ilbeigy Ghale Nei R, Rostami M. Role of religious attitudes, spiritual well-being and social support in predicting the life satisfaction in mothers of mental retardation children. Islam and Health Journal. 2014;1(3):41-49. [Persian].

13. Smith L, Webber R, DeFrain J. Spiritual well-being and its relationship to resilience in young people: a mixed methods case study. Sage Open. 2013;3(2):2158244013485582. doi: 10.1177/2158244013485582.

14. Hosseini Ghomi T, Salami Bajestani H. The relationship between religious orientation and resiliency among mothers of children with diseases. Ravanshenasi Va Din. 2011;4(3):69-82. [Persian].

15. McDermid F, Peters K, Daly J, Jackson D. Developing resilience: Stories from novice nurse academics. Nurse Educ Today. 2016;38:29-35. doi: 10.1016/j. nedt.2016.01.002.

16. Caldeira S, Timmins F. Resilience: synthesis of concept analyses and contribution to nursing classifications. Int Nurs Rev. 2016;63(2):191-9. doi: 10.1111/inr.12268.

17. Agaibi CE, Wilson JP. Trauma, PTSD, and resilience: a review of the literature. Trauma Violence Abuse. 2005;6(3):195-216. doi: 10.1177/1524838005277438.

18. HeimanT. Parents of children with disabilities: resilience, coping, and future expectations. J Dev Phys Disabil. 2002;14(2):159-71. doi: 10.1023/A:1015219514621.

19. Purdy IB, Melwak MA, Smith JR, Kenner C, ChuffoSiewert R, Ryan DJ, et al. Neonatal nurses NICU quality improvement: embracing EBP recommendations to provide parent psychosocial support. Adv Neonatal Care. 2017;17(1):33-44. doi: 10.1097/ anc.0000000000000352.

20. McCormack LA, Treiman K, Rupert D, WilliamsPiehota P, Nadler E, Arora NK, et al. Measuring patientcentered communication in cancer care: a literature review and the development of a systematic approach. Soc Sci Med. 2011;72(7):1085-95. doi: 10.1016/j. socscimed.2011.01.020.

21. Neumann $M$, Bensing J, Mercer $S$, Ernstmann $N$, Ommen O, Pfaff H. Analyzing the "nature" and "specific effectiveness" of clinical empathy: a theoretical overview and contribution towards a theory-based research agenda. Patient Educ Couns. 2009;74(3):33946. doi: 10.1016/j.pec.2008.11.013.

22. Morse DS, Edwardsen EA, Gordon HS. Missed opportunities for interval empathy in lung cancer communication. Arch Intern Med. 2008;168(17):18538. doi: 10.1001/archinte.168.17.1853.

23. Wei X, Shi Z. Nurses' communication ability in nursepatient conflict. J Nurs Sci. 2010;25(9):57-9.

24. Wigert $H$, Dellenmark MB, Bry K. Strengths and weaknesses of parent-staff communication in the NICU: a survey assessment. BMC Pediatr. 2013;13:71. doi: 10.1186/1471-2431-13-71.

25. Mohammady M, Shirani F, Sadeghi M. Bias in the clinical trials: a review article. Journal of Urmia Nursing and Midwifery Faculty. 2018;16(4):273-85. [Persian].

26. Kelley KJ, Kelley MF. Teaching empathy and other compassion-based communication skills. J Nurses 
Prof Dev. 2013;29(6):321-4. doi: 10.1097/01. nnd.0000436794.24434.90.

27. Hojat M. Ten approaches for enhancing empathy in health and human services cultures. J Health Hum Serv Adm. 2009;31(4):412-50.

28. Connor KM, Davidson JR. Development of a new resilience scale: the Connor-Davidson resilience scale (CD-RISC). Depress Anxiety. 2003;18(2):76-82. doi: 10.1002/da.10113.

29. Abdi F, Banijamli S, Ahadi H, Koushki S. Psychometric properties of of resilience scale (CD-RISC) among women's with breast cancer. Research in Psychological Health. 2019;13(2):81-99. [Persian].

30. Hosseini SS, Baniasadi H, Pouraboli B. Stressors of parents of hospitalized preterm infants: a study in neonatal intensive care unit of Afzalipour hospital, Kerman, Iran. Health and Development Journal. 2020 Aug 24;4(4):337-48. [Persian].

31. Ahmadi Z, Ashrafi F, Seyed Fatemi N, Haghani $H$. Relationship between social support with self-efficacy and blues maternity amonug nulliparous mothers with premature infants admitted to the Neonatal Intensive Care Unit. Iranian Journal of Pediatric Nursing. 2018;4(4):74-80. [Persian].
32. Askari M, Asgari P, Bahramnezhad F, Sohrabi S. The effects of an empowerment program on the mother infant attachment in primigravidity women. J Sabzevar Univ Med Sci. 2019;26(2):255-62. [Persian].

33. Nuri HR, Shahabi B. The effectiveness of selfcompassion training on increase of mothers'resiliency with autistic children. Knowledge \& Research in Applied Psychology. 2017;18(3):118-26. [Persian].

34. Segre LS, Chuffo-Siewert R, Brock RL, O'Hara MW. Emotional distress in mothers of preterm hospitalized infants: a feasibility trial of nurse-delivered treatment. J Perinatol. 2013;33(12):924-8. doi: 10.1038/jp.2013.93.

35. Shameli R, Hasani F. The effectiveness of reality therapy on resilience in mothers with children afflicted by cancer. Thought \& Behavior in Clinical Psychology. 2017;11(43):77-86. [Persian].

36. Asghari Nekah SM, Jansooz F, Kamali F, Taherinia S. The resiliency status and emotional distress in mothers of children with cancer. J Clin Psychol. 2015;7(1):1526. [Persian].

37. Hynan MT, Hall SL. Psychosocial program standards for NICU parents. J Perinatol. 2015;35 Suppl 1:S1-4. doi: 10.1038/jp.2015.141. 